ORIGINAL ARTICLE

\title{
Effects of intra-session concurrent endurance and strength training sequence on aerobic performance and capacity
}

\author{
M Chtara, K Chamari, M Chaouachi, A Chaouachi, D Koubaa, Y Feki, G P Millet, M Amri
}

Br J Sports Med 2005;39:555-560. doi: 10.1136/bjsm.2004.015248

See end of article for authors' affiliations

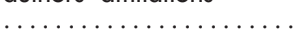

Correspondence to: K Chamari, National Center of Medicine and Sciences in Sports, Physiology Department, Unité de Recherche "Evaluation, Sport, Santé", BP 263, Ave Mohamed Ali Akid, El Menzah 1004, Tunisia; karimchamari@gmx.net

Accepted 10 November 2004

\begin{abstract}
Aim: To examine the effects of the sequencing order of individualised intermittent endurance training combined with muscular strengthening on aerobic performance and capacity.

Methods: Forty eight male sport students (mean (SD) age 21.4 (1.3) years) were divided into five homogeneous groups according to their maximal aerobic speeds ( $\left.\vee \mathrm{V}_{2} \mathrm{MAX}\right)$. Four groups participated in various training programmes for 12 weeks (two sessions a week) as follows: $E$ ( $n=10$ ), running endurance training; $S(n=9)$, strength circuit training; $E+S(n=10)$ and $S+E(n=10)$ combined the two programmes in a different order during the same training session. Group $C(n=9)$ served as a control. All the subjects were evaluated before (TO) and after (T1) the training period using four tests: (1) a $4 \mathrm{~km}$ time trial running test; (2) an incremental track test to estimate $v \dot{V O}_{2} \mathrm{MAX}$; (3) a time to exhaustion test ( $t_{\text {lim }}$ ) at $100 \% \vee \dot{V} \mathrm{O}_{2} \mathrm{MAX} ;(4)$ a maximal cycling laboratory test to assess $\mathrm{VO}_{2} \mathrm{MAX}$.

Results: Training produced significant improvements in performance and aerobic capacity in the $4 \mathrm{~km}$ time trial with interaction effect $(\mathrm{p}<0.001)$. The improvements were significantly higher for the $\mathrm{E}+\mathrm{S}$ group than for the $\mathrm{E}, \mathrm{S}+\mathrm{E}$, and $\mathrm{S}$ groups: $8.6 \%, 5.7 \%, 4.7 \%$, and $2.5 \%$ for the $4 \mathrm{~km}$ test $(\mathrm{p}<0.05) ; 10.4 \%, 8.3 \%$, $8.2 \%$, and $1.6 \%$ for $v \dot{\mathrm{O}_{2}} \mathrm{MAX}(\mathrm{p}<0.01) ; 13.7 \%, 10.1 \%, 11.0 \%$, and $6.4 \%$ for $\mathrm{VO}_{2} \mathrm{MAX}\left(\mathrm{ml} / \mathrm{kg}^{0.75} / \mathrm{min}\right)$ $(p<0.05)$ respectively. Similar significant results were observed for $t_{\lim }$ and the second ventilatory threshold $\left(\% \mathrm{VO}_{2} \mathrm{MAX}\right)$.

Conclusions: Circuit training immediately after individualised endurance training in the same session $(E+S)$ produced greater improvement in the $4 \mathrm{~km}$ time trial and aerobic capacity than the opposite order or each of the training programmes performed separately.
\end{abstract}

$\mathrm{T}$ he development of the various components of muscular strength is now integrated into the training programmes of various endurance disciplines. The high level of velocity and power sustained and the imposed changes in pacing require emphasis on muscular preparation. Various studies have shown the benefit of adding strength training to improve endurance performance. ${ }^{1-4}$

Theoretically, training induced muscle adaptations are divergent and can even be antagonistic to improvements in strength $^{5-7}$ or endurance. ${ }^{8}{ }^{9}$ Strength training has been reported to cause muscle fibre hypertrophy, associated with an increase in contractile protein, proportional to an increase in maximal contractile force. ${ }^{10}$ Strength training also reduces mitochondrial density and decreases the activity of oxidative enzymes, which can impede endurance capacity, but has minimal effect on capillary density or the conversion from fast (type II) to slow twitch (type I) fibre types. ${ }^{8}{ }^{10}$ In contrast, endurance training usually induces little or no muscle hypertrophy, but increases the mitochondrial content, citric acid enzymes, oxidative capacity, and the possibility of muscle fibre conversion from fast to slow twitch. ${ }^{811}$ The interference between endurance and strength training can be explained by the followings factors: (a) the inability of muscle to adapt optimally to two different stimuli because of simultaneous requests from different energy pathways during the same session ${ }^{72} ;(b)$ muscle tiredness resulting from the preceding training ${ }^{13}{ }^{14} ;(c)$ the type, nature, and specific mode of strength and aerobic training ${ }^{15}$ as well as the physical fitness and age of the athletes ${ }^{3}{ }^{12} ;(d)$ the volume, frequency, and intensity of training may also influence the degree of incompatibility observed ${ }^{92}$; (e) finally, the sequencing order-that is, the order in which endurance and strength training are carried out-may also have an effect on the training induced adaptations. ${ }^{10}{ }^{16-18}$ However, only a few studies have reported whether strength training should precede or follow endurance training when both are performed in the same session. ${ }^{17}{ }^{18}$ Previous investigations on the effects of concurrent training have used various sequences: (a) periods of several weeks of strength training before endurance training or endurance training before strength training ${ }^{519}{ }^{20} ;(b)$ alternating training days during the training period ${ }^{10}{ }^{16} ;(c)$ alternating the sequences during the training sessions. ${ }^{17}{ }^{18}$ In the latter studies, aerobic capacity improved. However, to the best of our knowledge, there are no studies on the effect of the sequence order of concurrent training in the same session on endurance performance.

Therefore the objectives of this study were firstly to examine the effects of concurrent strength and endurance training on aerobic performance, and secondly to determine if the order of training within the same session produces different changes in endurance performance.

\section{METHODS}

\section{Subjects}

Forty eight male sports students participated in the study. They did not do any physical activity outside of their studies (about 15 hours of multiple activities a week). All subjects gave written consent after having being informed about the study protocol, without being informed of the goal of the study. The study protocol was approved by the National University ethics committee. Anthropometric characteristics were as follows: mean (SD) age 21.4 (1.3) years; height 178.2 (5.7) $\mathrm{cm}$; body mass 72.1 (6.3) kg; percentage body fat 14.7 $(3.0) \%$. Mean (SD) aerobic maximal speed $\left(v \dot{\mathrm{V}}_{2} \mathrm{MAX}\right)$ and maximum oxygen consumption $\left(\dot{\mathrm{V}}_{2} \mathrm{MAX}\right)$ were 16.16 $(0.85) \mathrm{km} / \mathrm{h}$ and 50.60 (4.24) $\mathrm{ml} / \mathrm{kg} / \mathrm{min}$ respectively. The subjects were divided into five homogeneous groups according to their $v \dot{\mathrm{V}}_{2} \mathrm{MAX}$. 


\section{Protocol}

Four groups participated in various training programmes for 12 weeks (two sessions a week) as follows: group E ( $\mathrm{n}=$ $10)$, running endurance training; group $S(n=9)$, strength circuit training; groups $\mathrm{E}+\mathrm{S}(\mathrm{n}=10)$ and $\mathrm{S}+\mathrm{E}(\mathrm{n}=10)$ combined the two training methods in different orders during the same training session. Group $\mathrm{C}(\mathrm{n}=9)$ served as a control. Before (T0, February) and after (Tl, May) the training period, each subject performed the same evaluation protocol including anthropometric, field, and laboratory tests. The subjects did not perform any intense physical activity during the 24 hours preceding each test.

\section{Physiological measurements}

The subjects had field and laboratory tests during which they were greatly encouraged to reach their maximal performance.

\section{Field tests}

(1) A $4 \mathrm{~km}$ time trial: this consisted of covering $4 \mathrm{~km}$ in the minimum time on a $400 \mathrm{~m}$ athletic track. The test was preceded by a standardised 20 minute warm up period.

(2) A progressive Vam-eval track test for the measurement of maximal aerobic speed $\left(v \dot{\mathrm{V}}_{2} \mathrm{MAX}\right) .{ }^{21}$ This test consisted of a running trial around a $200 \mathrm{~m}$ track calibrated by reference marks placed every $20 \mathrm{~m}$. A tape recorder emitted sound signals, which indicated the speed to be achieved. The speed was low at the beginning $(8 \mathrm{~km} / \mathrm{h})$ and increased by $0.5 \mathrm{~km} / \mathrm{h}$ each minute. The last stage reached and completed by the subject corresponded to his maximal aerobic speed $\left(v \dot{\mathrm{V}}_{2} \mathrm{MAX}\right)$, which is considered an indicator of aerobic power. ${ }^{21} 29$

(3) A constant velocity test to exhaustion $\left(t_{\text {lim }}\right)$ at $100 \%$ $v \dot{\mathrm{V}}_{2}$ MAX. ${ }^{22}$ It was carried out on the same $200 \mathrm{~m}$ track with $20 \mathrm{~m}$ reference marks. The subject carried out a 15 minute warm up at $60 \%$ of $v \dot{\mathrm{V}}_{2} \mathrm{MAX}$. Then in 20 seconds, he reached his $v \dot{\mathrm{V}}_{2} \mathrm{MAX}$ and tried to maintain it for as long as possible. The assessor emitted sound signals, which indicated the speed to be achieved, thanks to a stop watch which allowed adjustable countdowns to the nearest $1 / 100$ seconds to be set. These countdowns and corresponding sound signals allowed the subject to maintain the imposed speed by reaching the successive marks for each sound signal. During the last two tests, heart rate (HR) was continuously recorded, using a heart rate monitor (Polar Accurex Plus, Kempele, Finland) set at a recording frequency of $0.2 \mathrm{~Hz}$ (five second intervals). At $\mathrm{Tl}$, the subjects performed the $\mathrm{t}_{\mathrm{lim}}$ test with the same $\mathrm{vV}_{2} \mathrm{MAX}$ as at T0. All the tests were performed in the morning (9-11 am). The external temperature varied between $25^{\circ} \mathrm{C}$ and $30^{\circ} \mathrm{C}$.

\section{Laboratory testing}

A continuous incremental test was carried out on an ergocycle (Ergoline type 800, Bitz, Germany). Laboratory testing was carried out from 2 to $5 \mathrm{pm}$ (temperature 21 (1) ${ }^{\circ} \mathrm{C}$ ). Before each test, the subjects had a clinical examination and resting electrocardiogram to check their health status. The test protocol was personalised by individualised increments. ${ }^{23}$ Cardiorespiratory variables were determined using a breath by breath system (ZAN 680, Oberthulba, Germany) allowing continuous measurement of HR, oxygen uptake, and lung ventilation. Before each test, the gas analysers were calibrated with gases of known concentration, and the ventilatory membrane with a 1 litre syringe. HR was determined from a six lead electrocardiograph with 12 derivations. HR and the respiratory data were provided once every 30 seconds, with the values averaged over the last 10 respiratory cycles on a sliding technique basis. ${ }^{24}$ Classical criteria of attainment of $\dot{\mathrm{V}}_{2} \mathrm{MAX}$ were observed in all subjects. ${ }^{78}$ The highest HR attained at exhaustion was considered to be $\mathrm{HR}_{\max }$. Respiratory compensation threshold $\left(\mathrm{Th} 2_{\mathrm{vent}}\right)$ was calculated by the method of Beaver et al. ${ }^{25}$ $\dot{\mathrm{V}} \mathrm{O}_{2} \mathrm{MAX}$ was expressed classically and according to allometric scaling to avoid underestimation in heavy subjects and overestimation in light subjects. ${ }^{26-28}$

\section{Training programmes}

\section{Endurance training (E)}

This was carried out on a $200 \mathrm{~m}$ track calibrated by $20 \mathrm{~m}$ reference marks. It included five successive fractions. Each fraction consisted of one period of exercise at 100\% of $v \dot{\mathrm{V}} \mathrm{O}_{2} \mathrm{MAX}$ and one period of active recovery at $60 \%$ of $v \dot{\mathrm{V}}_{2} \mathrm{MAX}$. The duration of each period was equal to half of the individual $t_{\text {lim }}$ duration. ${ }^{29}$ An assessor emitted sound signals, which indicated the speed to be achieved. Thereafter, the intensities of the periods of exercise and recovery were alternatively readjusted $(+5 \%)$ when the HR measured at the end of the fifth fraction of a given training session was lower by $10-12$ beats/min with respect to the first session performed at that particular intensity.

\section{Strength training $(S)$}

The programme was divided into four periods of three weeks each. During the first two periods, the general objective was the development of strength endurance. The exercises included total and segmentary movements of upper limbs, trunk and lower limbs (abdominal strengthening, hip extension with $15 \mathrm{~kg}$, back extensors, half squats with $20 \mathrm{~kg}$, forward alternated arm flexions with 5-10 kg, forward walking slits with $20 \mathrm{~kg}$ ). As far as periods 3 and 4 are concerned, particular emphasis was put on the development of explosiveness. The choice of the exercises mainly focused on the muscular chains particularly involved in running-

\begin{tabular}{|c|c|c|c|c|}
\hline & Cycle 1 & Cycle 2 & Cycle 3 & Cycle 4 \\
\hline Duration of cycle (weeks) & 3 & 3 & 3 & 3 \\
\hline Main objective & Strength endurance & Strength endurance & Explosivity & Explosivity \\
\hline $\begin{array}{l}\text { Number of exercises } \\
\text { per circuit }\end{array}$ & 6 & 6 & 6 & 6 \\
\hline $\begin{array}{l}\text { Number of circuit } \\
\text { revolutions (series) }\end{array}$ & 4 & 4 & 4 & 4 \\
\hline Work/rest (s) & $30 / 30$ & $40 / 20$ & $30 / 30$ & $40 / 20$ \\
\hline $\begin{array}{l}\text { Inter-series recovery } \\
\text { (min) }\end{array}$ & 2 & 2 & 2 & 2 \\
\hline $\begin{array}{l}\text { Total duration of the } \\
\text { session (min) }\end{array}$ & 30 & 30 & 30 & 30 \\
\hline
\end{tabular}




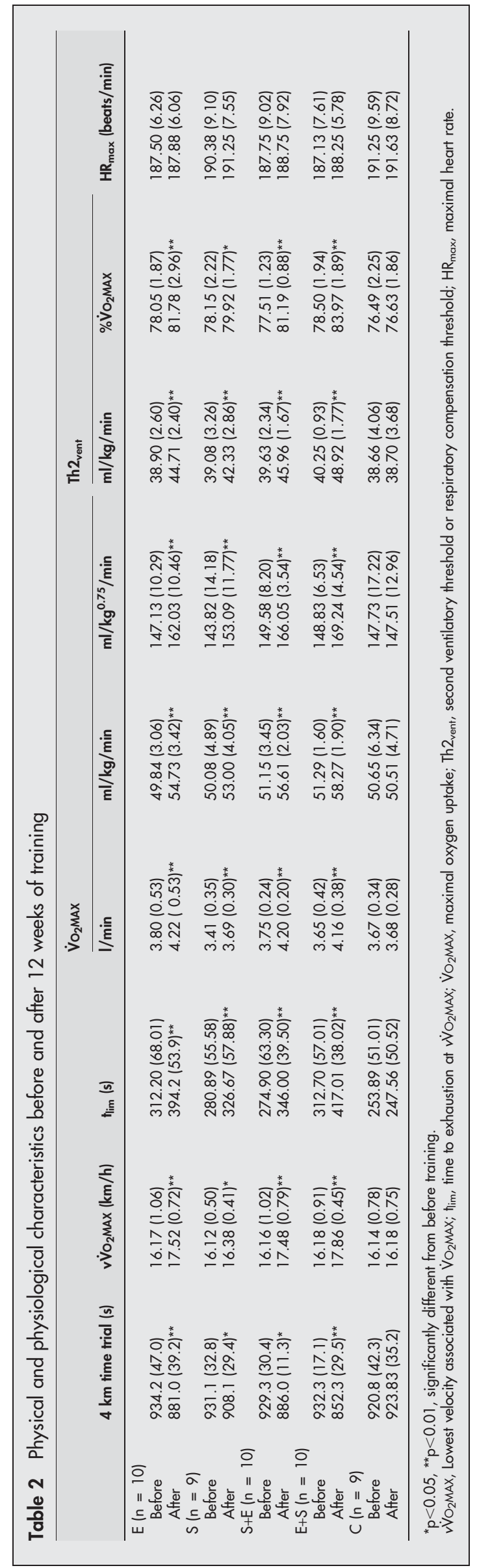

that is, lower limbs (drop jumps from a plinth $(0.30-0.60 \mathrm{~m})$, hops, jumps over hurdles $(0.50-0.70 \mathrm{~m})$, single leg hops, single leg bonds, multi-jumps). The subjects were trained by short interval circuits (30-30 seconds and 40-20 seconds). The warm up lasted about 15-20 minutes. Recovery between the circuits was set at two minutes, and the total session was about 30 minutes (warm up excluded). Exercise intensity was individual, as each subject was asked to perform an optimal number of repetitions per set, inducing fatigue on the one hand, and allowing him to complete the entire training session on the other. In parallel, throughout the training period, the exercises were made harder by increasing hurdle and plinth heights and jumps and bond length. Table 1 presents the programme as it was carried out.

The weekly inter-session interval was three days. Groups E and $S$ trained on Mondays and Thursdays, and groups E+S and S+E trained on Tuesdays and Fridays.

\section{Statistical analysis}

Paired $t$ tests were used to determine the significance of differences in the measured variables after training. When the normality test failed, a Mann-Whitney rank sum test was performed between pre-training and post-training variables. The data were then analysed using multivariate analysis of variance with repeated measures. Because of the slight differences in the initial groups, analysis of covariance with the pre-test values as the covariate was used to determine significant differences between the post-test adjusted means in the groups. The results are presented as means (SD). $\mathrm{p}<0.05$ was accepted as significant.

\section{RESULTS}

\section{$4 \mathbf{~ k m}$ time trial performance}

The $4 \mathrm{~km}$ performance had improved significantly after training (table 2). The improvements were as follows: group $\mathrm{E}+\mathrm{S}=8.57 \%$; group $\mathrm{E}=5.69 \%$; group $\mathrm{S}+\mathrm{E}=4.66 \%$; group $\mathrm{S}=2.47 \%$. The inter-group comparison shows that group $\mathrm{E}+\mathrm{S}$ had significantly higher averaged adjusted values than the $\mathrm{E}, \mathrm{S}+\mathrm{E}$, and $\mathrm{S}$ groups $(\mathrm{p}<0.05)$ (fig 1$)$.

\section{Variables of aerobic capacity}

The multivariate analysis of variance showed a significant interaction $(\mathrm{p}<0.001)$ between the two principal factors (group $\times$ time) for the maximal aerobic speed, $t_{\lim }$ performance, $\dot{\mathrm{V}}_{2} \mathrm{MAX} \quad\left(\mathrm{l} / \mathrm{min}, \mathrm{ml} / \mathrm{kg} / \mathrm{min}\right.$, and $\mathrm{ml} / \mathrm{kg}^{0.75}$, $\mathrm{min})$, and the respiratory compensation threshold $(\mathrm{ml} / \mathrm{kg} /$ min and $\left.\% \dot{\mathrm{V}}_{2} \mathrm{MAX}\right)$. After the 12 weeks of training, all physiological variables studied had improved significantly $(p<0.001)$, except $\mathrm{HR}_{\max }$. Moreover, a significant effect of the group factor was observed $(p<0.001)$. No changes were observed for the control group (table 2).

The univariate analysis of variance showed that training induced significant improvements in $\mathrm{vV}_{\mathrm{O}_{2}} \mathrm{MAX}$ for the four experimental groups: $10.38 \%$ for $\mathrm{E}+\mathrm{S}, 8.35 \%$ for $\mathrm{E}, \mathrm{8.17 \%}$ for $\mathrm{S}+\mathrm{E}$, and $1.61 \%$ for $\mathrm{S}$. E+S had significantly higher averaged adjusted values than the other groups $(\mathrm{p}<0.01)$ (fig $2 \mathrm{~A})$.

Training induced significant improvements in $t_{\text {lim }}$ performance for the four experimental groups: $28.22 \%$ for E+S, $21.13 \%$ for $\mathrm{E}, 20.80 \%$ for $\mathrm{S}+\mathrm{E}$, and $11.28 \%$ for $\mathrm{S}$. The E+S group had significantly higher averaged adjusted values than the other groups $(\mathrm{p}<0.02)$ (fig $2 \mathrm{~B})$.

Absolute (l/min) and scaled $\left(\mathrm{ml} / \mathrm{kg}^{0.75} / \mathrm{min}\right) \dot{\mathrm{V}}_{2} \mathrm{MAX}$ had improved significantly. The improvements in absolute $\dot{\mathrm{V}}_{2} \mathrm{MAX}(\mathrm{l} / \mathrm{min})$ were $14.05 \%$ for $\mathrm{E}+\mathrm{S}, 11.96 \%$ for $\mathrm{S}+\mathrm{E}$, $11.05 \%$ for $\mathrm{E}$, and $8.29 \%$ for $\mathrm{S}$. The improvements in scaled $\dot{\mathrm{V}}_{2} \mathrm{MAX}\left(\mathrm{ml} / \mathrm{kg}^{0.75} / \mathrm{min}\right)$ were $13.71 \%$ for $\mathrm{E}+\mathrm{S}, 11.01 \%$ for $\mathrm{S}+\mathrm{E}$, $10.13 \%$ for $\mathrm{E}$, and $6.45 \%$ for $\mathrm{S}$. For absolute $\dot{\mathrm{V}}_{2} \operatorname{MAX}(\mathrm{l} / \mathrm{min})$, groups E+S, E, and S+E showed comparable adjusted averaged values, whereas for scaled $\dot{\mathrm{V}}_{2} \operatorname{MAX}\left(\mathrm{ml} / \mathrm{kg}^{0.75} / \mathrm{min}\right)$, 


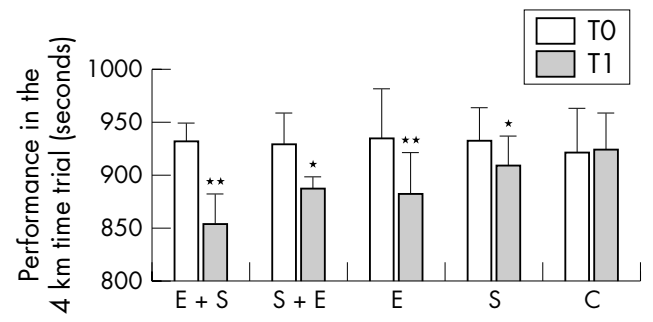

Pairwise comparisons
\begin{tabular}{|c|c|c|c|c|}
\hline & $S+E$ & $E$ & $S$ & $C$ \\
\hline$E+S$ & $\star \star$ & $\star$ & $\star \star$ & $\star \star$ \\
\hline \multirow{2}{*}{} & $S+E$ & $\S$ & $\star$ & $\star \star$ \\
\cline { 2 - 5 } & $E$ & $\star \star$ & $\star \star$ \\
\cline { 2 - 5 } & & $S$ & $\S$ \\
\cline { 3 - 5 }
\end{tabular}

Figure 1 Changes in the $4 \mathrm{~km}$ time trial after training. $\mathrm{E}+\mathrm{S}$, Endurance followed by strength training; $\mathrm{S}+\mathrm{E}$, strength followed by endurance training; $\mathrm{E}$, endurance training only; $S$, strength training only; C, control group. §Non-significant difference; ${ }^{*}$ significant difference, $p<0.05 ;{ }^{* *}$ significant difference, $p<0.01$.

group E+S showed significantly higher averaged adjusted values $(\mathrm{p}<0.04)$ (fig 3 ).

Th2 $2_{\text {vent }}$ increased by $21.54 \%$ and $6.96 \%$ for the E+S group, $14.93 \%$ and $4.77 \%$ for the E group, $15.99 \%$ and $4.75 \%$ for the S+E group, and $8.30 \%$ and $2.26 \%$ for the S group, when expressed in $\mathrm{ml} / \mathrm{kg} / \mathrm{min}$ or $\% \dot{\mathrm{VO}}_{2} \mathrm{MAX}$ respectively. The $\mathrm{E}+\mathrm{S}$ group had significantly higher averaged adjusted values than the $\mathrm{E}(\mathrm{p}<0.001)$ and $\mathrm{S}+\mathrm{E}(\mathrm{p}<0.03)$ groups.

\section{DISCUSSION}

This study confirms that concurrent strength and endurance training produces improvements in aerobic capacity and endurance performance. However, the improvements are greater when, in the same session, the endurance training precedes the strength training.

\section{Endurance training alone}

This study confirms that intermittent sessions using running velocity close to $v \dot{\mathrm{V}}_{2} \mathrm{MAX}$ are effective in improving aerobic power. ${ }^{30} 31$ These modifications are accompanied by an improvement in the $4 \mathrm{~km}$ test trial performance (table 2). This type of session, in which periods of high and moderate intensity are alternated, allows high intensities to be maintained for longer than a continuous training session.

\section{Strength training alone}

The use of short intermittent strength exercises was shown to affect aerobic capacity: the increase in $\dot{\mathrm{V}}_{2} \mathrm{MAX}$ observed during this study was close to that noted previously (8$10 \%)^{10} 12$ but is greater than that found in other studies. ${ }^{52} 33$ The magnitude of cardiorespiratory adaptation depends primarily on the intensity, duration, and frequency of the exercise. ${ }^{11}$ If the intensity of work during strength training is not sufficient, oxygen consumption remains very low-that is, only $45 \% \mathrm{~V}_{2}$ MAX. ${ }^{32}$ To reach a positive effect, it seems that a minimal level of intensity of $50 \% \dot{\mathrm{V}}_{2} \mathrm{MAX}$ has to be attained. ${ }^{34}$ Furthermore, the training duration was only 15 minutes three times a week. Of the other studies that did not show cardiorespiratory improvement with strength training, that of Hickson ${ }^{5}$ was composed of traditional strength exercises including short series (five repetitions, with heavy loads of $>80 \%$ of maximum) and long (three minutes) rests. It is clear that this type of training does not fulfil the commonly acknowledged requirements of duration and intensity for endurance work. In this context, this study of strength training allowed long duration exercises which certainly helped to improve aerobic capacity. Lastly, the optimal duration for improvements in $\dot{\mathrm{V}}_{2} \mathrm{MAX}$ with strength training has been reported to be 1012 weeks, ${ }^{5} 101232$ but significant improvement has also been noted with a shorter period-that is, seven weeks. ${ }^{33}$

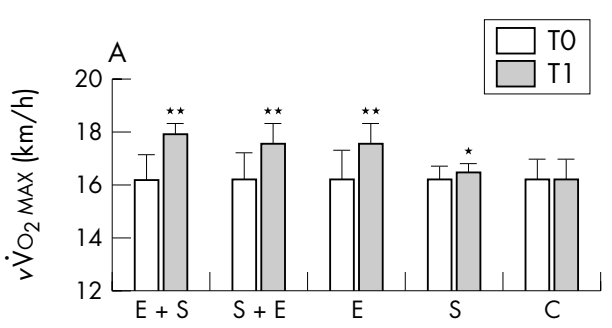

Pairwise comparisons
\begin{tabular}{|c|c|c|c|c|}
\hline & $S+E$ & $E$ & $S$ & $C$ \\
\hline$E+S$ & $\star \star$ & $\star \star$ & $\star \star$ & $\star \star$ \\
\hline \multirow{2yyyy}{*}{} & $S+E$ & $\S$ & $\star \star$ & $\star \star$ \\
\cline { 2 - 5 } & $E$ & $\star \star$ & $\star \star$ \\
\cline { 2 - 5 } & & $S$ & $\S$ \\
\hline
\end{tabular}

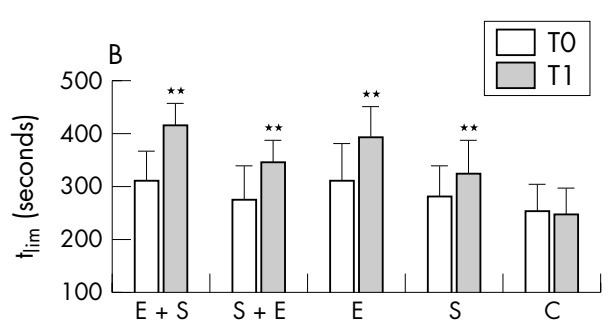

Pairwise comparisons
\begin{tabular}{|c|c|c|c|c|}
\hline & $S+E$ & $E$ & $S$ & $C$ \\
\hline$E+S$ & $\star \star$ & $\star$ & $\star \star$ & $\star \star$ \\
\hline \multirow{2}{*}{} & $S+E$ & $\star$ & $\star \star$ & $\star \star$ \\
\cline { 2 - 5 } & $E$ & $\star \star$ & $\star \star$ \\
\cline { 2 - 5 } & & S & $\star \star$ \\
\hline
\end{tabular}

Figure 2 Changes in $(A)$ the velocity associated with $\dot{V}_{2} \operatorname{MAX}(\mathrm{km} / \mathrm{h})$ and $(B)$ the time to exhaustion at $v \dot{V}_{2} M A X(t$ lim $)$ after training. E+S, Endurance followed by strength training; $S+E$, strength followed by endurance training; $E$, endurance training only; $S$, strength training only; $C$, control group. $\S$ Non-significant difference; ${ }^{*}$ significant difference, $\mathrm{p}<0.05$; ** significant difference, $\mathrm{p}<0.01$. 

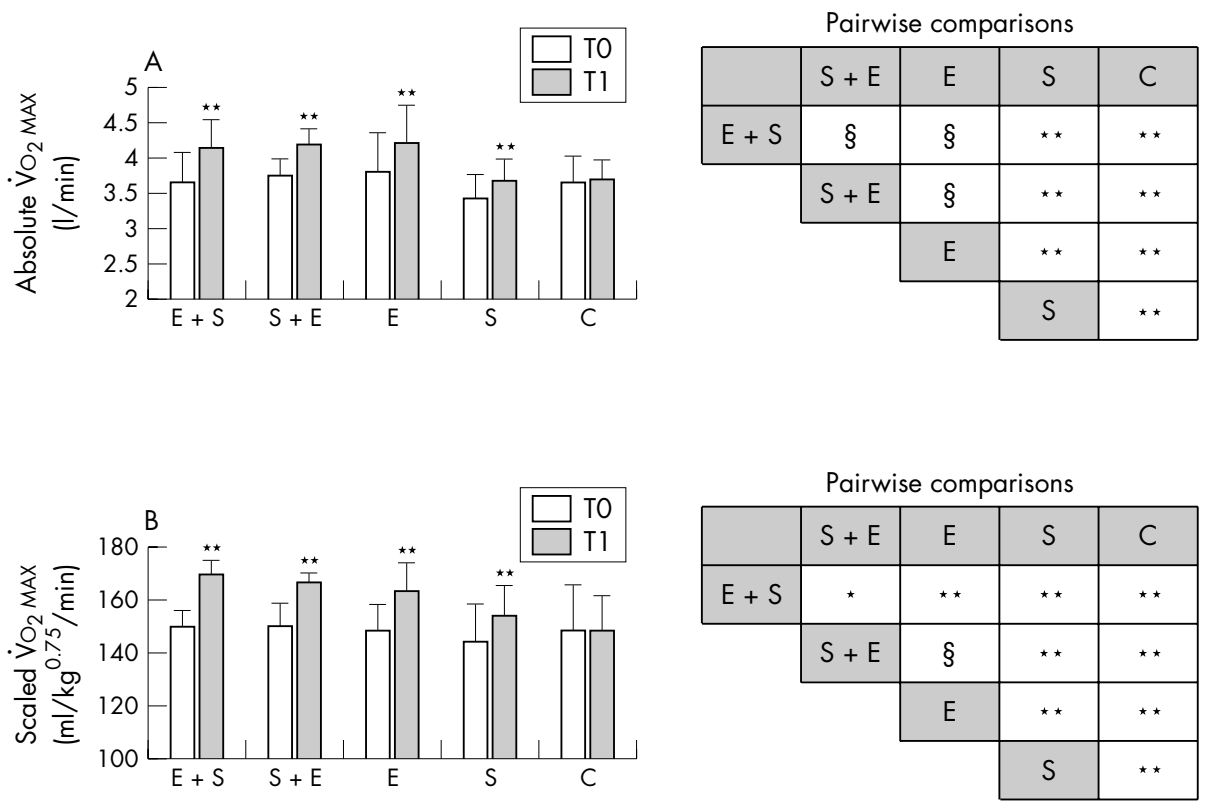

Figure 3 Changes in (A) absolute $\mathrm{V}_{2} \mathrm{MAX}(\mathrm{l} / \mathrm{min})$ and $(\mathrm{B})$ scaled $\mathrm{V}_{2} \mathrm{MAX}\left(\mathrm{ml} / \mathrm{kg}^{0.75} / \mathrm{min}\right)$ after training. $\mathrm{E}+\mathrm{S}$, Endurance followed by strength training; $S+E$, strength followed by endurance training; $E$, endurance training only; $S$, strength training only; $C$, control group. §Non-significant difference; ${ }^{*}$ significant difference, $\mathrm{p}<0.05 ;{ }^{* *}$ significant difference, $\mathrm{p}<0.01$.

\section{Concurrent strength and endurance training}

The concurrent training in this study produced significant improvements in the $4 \mathrm{~km}$ performance as well as aerobic capacity (table 2). This confirms the efficiency of this method in trained and non-trained subjects. ${ }^{1-4} 123335$ Tanaka and Swensen ${ }^{1}$ suggested that runners and cyclists may improve endurance performance by resistive weight training, because of increases in the size of type I fibres and changes in type II subtype ratios and myofibril contractile properties. These changes may allow a subject to exercise for longer at a given submaximal work rate by reducing the force contribution from each active myofibre or by using fewer myofibrils. In conjunction, the myofibre changes may also allow the recruitment of the less efficient type II fibres to be delayed. ${ }^{1}$ Hoff et $a l^{4}$ reported a considerable increase in endurance performance as the result of strength training in cross country skiers, which made them stronger, more powerful, and, especially, more economical. Paavolaïnen et $a l^{2}$ showed that endurance performance can be increased by adding explosive strength training (33\% of training time) to classic endurance training. Balabinis et $a l^{33}$ concluded that concurrent training was more effective in terms of performance increase than strength and endurance training alone. Lastly, McCarthy et $a l^{12}$ and Marcinik et $a l^{35}$ showed that heavy resistance strength training led to lower lactataemia at a given intensity, because of a reduction in intrafibre pressure, partly explaining the improvement in submaximal endurance performance.

\section{Concurrent training versus endurance or strength training}

Absolute $(\mathrm{l} / \mathrm{min})$ and relative $\left(\mathrm{ml} / \mathrm{kg}^{0.75} / \mathrm{min}\right) \dot{\mathrm{V}}_{2} \mathrm{MAX}$ had improved considerably after the various training programmes (table 2). For absolute $\dot{\mathrm{V}}_{2} \mathrm{MAX}$, the $\mathrm{E}+\mathrm{S}, \mathrm{E}$, and $\mathrm{S}+\mathrm{E}$ groups showed comparable adjusted average values, whereas relative $\dot{\mathrm{V}}_{2} \mathrm{MAX}$ had increased more in the $\mathrm{E}+\mathrm{S}$ group than the other groups (fig 3 ). This shows that expressing $\dot{\mathrm{V}}_{2} \mathrm{MAX}$ appropriately is paramount as it may allow smaller changes to be observed. The improvements in the combined groups were slightly higher than those observed in previous studies using similar concurrent training. ${ }^{70} 14{ }^{17}$ In contrast with our study, no changes in $\dot{\mathrm{V}}_{2} \mathrm{MAX}$ were observed in previous studies. $^{2-35932}$ These differences can be explained by the training programmes (form, intensity, frequency, and duration), the initial level, and the age and sex of the subjects. Other mechanisms may be involved, including particularly the conflict between the physiological adaptations, in addition to muscular hypertrophy which produces an increase in body mass. ${ }^{6}$

$v \dot{\mathrm{V}}_{2} \mathrm{MAX}$ had improved notably more for the $\mathrm{E}+\mathrm{S}$ group than the E and S+E groups (fig 2A). Millet et $a l^{3}$ showed that, in triathletes, $v \dot{\mathrm{V}} \mathrm{O}_{2} \mathrm{MAX}$ increased by $6.7 \%(\mathrm{p}<0.01)$ in a combined group and did not change in an endurance group $(2.6 \%)$. Paavolaïnen et $a l^{2}$ also reported an increase in $v \dot{\mathrm{V}}_{2} \mathrm{MAX}(\mathrm{p}<0.05)$ in a combined group and not in an endurance group and suggested that it was mainly due to a change in lower limb power and strength.

\section{Endurance and strength training sequencing}

The most important finding of this study was that the intrasession order of strength and endurance training influences the training induced adaptations. The improvement in $\dot{\mathrm{V}}_{2} \operatorname{MAX}(\mathrm{ml} / \mathrm{kg} / \mathrm{min})$ was greater in the $\mathrm{E}+\mathrm{S}$ group than in the S+E group (13.6\% $v 10.7 \%$ ) (table 2). Previous studies have examined the effects of intra-session sequence order of strength and endurance training on aerobic adaptations. Collins and Snow ${ }^{17}$ showed that the training sequence did not have any effect on the change in $\dot{\mathrm{V}}_{2}$ MAX. Gravelle and Blessing $^{18}$ reported that concurrent training limited the increase in $\dot{\mathrm{VO}}_{2} \mathrm{MAX}$ when endurance training preceded strength training compared with strength before endurance training $(5.3 \% v 8.0 \%)$ in female students. It was argued that, when strength training was preceded by acute bouts of endurance and exhaustive dynamic resistance exercise, the subsequent strength training intensity was impaired, resulting in less strength improvement. The authors stressed the fact that it is still not known if the reverse was true. Our results may be partly explained by fatigue resulting from the strength training which may have influenced at least the physiological adaptations to endurance training, ${ }^{18}$ despite the fact that, from the training records, the endurance training intensity was not modified. Any possible effect of 


\section{What is already known on the topic}

Recent studies have shown that adding strength training to endurance training improves both aerobic capacity and endurance performance. However, the effects on endurance performance of the order in which the two types of training are performed in the same session have not been studied.

\section{What this study adds}

Endurance training followed by strength training produced greater improvements in endurance performance and aerobic capacity than the reverse order or if the training methods were performed separately.

fatigue has probably been counterbalanced by the positive effects of concurrent strength training, ${ }^{23}$ as the S+E group showed similar improvement in aerobic capacity and performance to the E group. However, it seems that the best sequence for aerobic adaptations consists of endurance training with no preceding fatigue followed by the strength circuit training with its well known effects on endurance performance and capacity.

To our knowledge, this study is the first to show the effects of intra-session sequence of training on endurance performance. As the S+E group improved all aspects of aerobic fitness, we can assume that the first activity (strength training) induced muscular fatigue which reduced the effectiveness of and/or physiological adaptations to the second activity (endurance training). Other factors such as endocrinal changes or alterations in the recruitment of the driving units may also be the origin of the differences observed. ${ }^{6}$

\section{CONCLUSION}

The intra-session order of strength and endurance training influenced the adaptive responses to them. Improvement in endurance performance and aerobic capacity was significantly greater when, in the same session, the endurance training preceded the strength training rather than the other way around or if each of the training methods was performed separately.

\section{ACKNOWLEDGEMENTS}

We thank Dr Zakia Bartagi, Dr Ali Ben Khedher, and Dr Mourad Hambli for invaluable help.

\section{Authors' affiliations}

M Chtara, M Chaouachi, M Amri, Laboratoire de Physiologie de la Nutrition, Faculté des Sciences de Tunis, El Manar, Tunisia

K Chamari, A Chaouachi, D Koubaa, National Center of Medicine and Sciences in Sports (NCMSS), El Menzah, Tunisia

G P Millet, UPRES 37-59, Faculty of Sports Sciences, University of Montpellier, Montpellier, France

Y Feki, Institut Supérieur du Sport et de l'Education Physique, Ksar Said, Tunisia

Competing interests: none declared

This study was financially supported by Ministère de la Recherche Scientifique, de la Technologie et du développement des Compétences, Tunisia

\section{REFERENCES}

1 Tanaka H, Swensen T. Impact of resistance training on endurance performance. A new form of cross training? Sports Med 1998;25:191-200.
2 Paavolaïnen L, Häkkinen K, Hämäläinen I, et al. Explosive-strength training improves $5-\mathrm{km}$ running time by improving running economy and muscle power. J Appl Physiol 1999;86:1527-33.

3 Millet GP, Jaouen B, Borrani F, et al. Effects of concurrent endurance and strength training on running economy and $\mathrm{VO}_{2}$ kinetics. Med Sci Sports Exerc 2002;34:1351-9.

4 Hoff J, Gran A, Helgerud J. Maximal strength training improves aerobic endurance performance. Scand J Med Sci Sports 2002;12:288-95.

5 Hickson RC. Interference of strength development by simultaneously training for strength and endurance. Eur J Appl Physiol 1980;45:255-63.

6 Leveritt M, Abernethy PJ, Barry BK, et al. Concurrent strength and endurance training. A review. Sports Med 1999;28:413-27.

7 Bell GJ, Syrotuik D, Martin TP, et al. Effect of concurrent strength and endurance training on skeletal muscle properties and hormone concentrations in humans. Eur J Appl Physiol 2000;81:418-27.

8 Nelson AG, Arnall DA, Loy SF, et al. Consequences of combining strength and endurance regimens. Phys Ther 1990;70:287-94.

9 Bishop D, Jenkins DG. The effects of strength training on endurance performance and muscle characteristics. Med Sci Sports Exerc 1999;31:886-91.

10 Sale DS, MacDougall JD, Jacobs I, et al. Interaction between concurrent strength and endurance training. J Appl Physiol 1990;68:260-70.

11 Åstrand P-O, Rodahl K. Physiological bases of exercise. Textbook of work physiology. 3rd ed. New York: McGraw-Hill, 1986.

12 McCarthy JP, Agre JC, Graf BK, et al. Compatibility of adaptive responses with combining strength and endurance training. Med Sci Sports Exerc 1995; 27:429-36.

13 Craig BW, Lucus J, Pohlman R, et al. Effects of running, weightlifting and a combination of both on growth hormone release. J Appl Sports Sci Res 1991;5:198-203.

14 Hennessy LC, Watson AWS. The interference effects of training for strength and endurance simultaneously. J Strength Cond Res 1994;8:12-19.

15 Häkkinen K, Komi PV, Alen M. Effects of explosive type strength training on isometric force- and relaxation-time, electromyographic and muscle fibre characteristics of leg extensor muscles. Acta Physiol Scand 1985; 125:587-600.

16 Bell GJ, Petersen SR, Quinney HA, et al. Sequencing of endurance and highvelocity strength training. Can J Sports Sci 1988;13:214-19.

17 Collins MA, Snow TK. Are adaptations to combined endurance and strength training affected by the sequence of training? J Sports Sci 1993;11:485-91.

18 Gravelle BL, Blessing DL. Physiological adaptation in women concurrently training for strength and endurance. J Strength Cond Res 2000;14:5-13.

19 Hunter G, Demment R, Miller D. Development of strength and maximum oxygen uptake during simultaneous training for strength and endurance. J Sports Med Phys Fitness 1987;27:269-75.

20 Lee A, Craig BW, Lucas J, et al. The effect of endurance training, weight training, and a combination of endurance and weight training upon the blood lipid profile of young male subjects. J App/ Sports Sci Res 1990;4:68-75.

21 Cazorla G. Tests de terrain pour évaluer la capacité aérobie et la vitesse maximale aérobie. In: Cazorla G, Robert et $G$. L'évaluation en activité physique et en sport. Cestas: AREAPS, 1990;151-74.

22 Billat V, Renoux JC, Pinoteau J, et al. Reproducibility of running time to exhaustion at $\mathrm{VO}_{2 \max }$ in sub-elite runners. Med Sci Sports Exerc 1994:26:254-7.

23 Hansen JE, Sue DY, Oren A, et al. Relation of oxygen uptake to work rate in normal men and men with circulatory disorders. Am J Cardiol 1987;59:669-74

24 Whipp BJ, Ward SA, Lamarra N, et al. Parameters of ventilatory and gas exchange dynamics during exercise. J Appl Physiol 1982;52:1506-13.

25 Beaver WL, Wasserman K, Whipp BJ. A new method for detecting anaerobic threshold by gas exchange. J Appl Physiol 1986;60:2020-7.

26 Wisleff U, Helgerud J, Hoff J. Strength and endurance of elite soccer players. Med Sci Sports Exerc 1998;30:462-7.

27 Bergh U, Sjødin B, Forsberg A, et al. The relationship between body mass and oxygen uptake during running in humans. Med Sci Sports Exerc $1991 ; 23: 205-11$

28 Chamari K, Hachana $Y$, Ben Ahmed $Y$, et al. Field and laboratory testing in young elite soccer players. Br J Sports Med 2004;38:191-6.

29 Billat $\mathrm{V}$, Flechet $\mathrm{B}$, Petit $\mathrm{B}$, et al. Interval training at $\mathrm{VO}_{2 \text { max }}$ : effects on aerobic performance and over training markers. Med Sci Sports Exerc 1999;31:156-63

30 Billat LV, Slavinski J, Bocquet V, et al. Intermittent runs at the velocity associated with maximal oxygen uptake enables subjects to remain at maximal oxygen uptake for a longer time than submaximal runs. Eur J Appl Physiol 2000;81:188-96.

31 Laursen PB, Shing CM, Peake JM, et al. Interval training program optimization in highly trained endurance cyclists. Med Sci Sports Exerc 2002;34:1801-7.

32 Hurley BF, Seals DR, Eshani AA, et al. Effects of high intensity strength training on cardiovascular functions. Med Sci Sports Exerc 1984;16:483-8.

33 Balabinis $\mathrm{CP}$, Psarakis $\mathrm{CH}$, Moukas $\mathrm{M}$, et al. Early phase changes by concurrent endurance and strength training. J Strength Cond Res 2003; 17:393-401.

34 Davies CT, Knibbs AV. The training stimulus: the effect of intensity duration and frequency of effort on aerobic power output. Int $Z$ Angew Physiol 1971;29:299-305.

35 Marcinik EJ, Potts J, Schlabach G, et al. Effects of strength training on lactate threshold and endurance performance. Med. Sci Sports Exerc $1991 ; 23: 739-43$ 